\title{
WSRC-TR-2003-00235
}

\section{The Dissolution of Uranium Oxides in HB-Line Phase I Dissolvers}

\author{
John H. Gray \\ Westinghouse Savannah River Company \\ Aiken, SC 29808
}

\section{Summary}

A series of characterization and dissolution studies has been performed to define flowsheet conditions for the dissolution of uranium oxide materials in HB-Line Phase I dissolvers. The samples selected for analysis were uranium oxide materials originally from Rocky Flats and recently shipped to the Savannah River Site. The selection of these uranium oxide materials for characterization and dissolution studies was based on high enriched uranium content and trace levels of plutonium.

Test results from the characterization study identified ferric oxide $\left(\mathrm{Fe}_{2} \mathrm{O}_{3}\right)$ and iron/chromium/nickel $(\mathrm{Fe} / \mathrm{Cr} / \mathrm{Ni})$ particles as impurities along with the tri-uranium oxide $\left(\mathrm{U}_{3} \mathrm{O}_{8}\right)$ and uranium trioxide $\left(\mathrm{UO}_{3}\right)$. The weight percent uranium in this material was found to vary depending on the impurity content. The trace impurity plutonium appears to be associated with the $\mathrm{Fe} / \mathrm{Cr} / \mathrm{Ni}$ particles. A small amount of absorbed moisture and waters of hydration is present.

Most of the uranium oxides easily dissolved in low-molar nitric acid solutions without fluoride within one to two hours at solution temperatures between $60-80^{\mathrm{O}} \mathrm{C}$. A small amount of residue remained following this dissolution step. To assure complete dissolution of uranium from these oxide materials, an additional dissolution step at $90^{\mathrm{O}} \mathrm{C}$ to boiling for at least one to two hours has been suggested. Only trace amounts of iron associated with $\mathrm{Fe}_{2} \mathrm{O}_{3}$ and $\mathrm{Fe} / \mathrm{Cr} / \mathrm{Ni}$ particles will dissolve during the dissolution steps. Neither hydrogen nor heat will be generated during the dissolution of these uranium oxide materials in nitric acid solutions. Some brown nitrogen dioxide $\left(\mathrm{NO}_{2}\right)$ fumes will be generated during the dissolution of $\mathrm{U}_{3} \mathrm{O}_{8}$.

\section{Introduction}

The enriched uranium recovered from these uranium oxide materials will be blended down with depleted uranium before shipment to the Tennessee Valley Authority. One of the selection bases for dissolution in HB-Line Phase I dissolvers is the need for geometrically favorable equipment during the generation of 100 grams per liter uranium solutions. However, the limitations introduced by using slab tanks without cooling coils and with a limited air purge through the dissolvers necessitated additional studies involving the generation of heat and hydrogen during dissolution. Measurement of nitric acid consumption was performed during the dissolution studies to calculate starting nitric acid concentrations required to address the final free acid concentration target of around two molar.

\section{Experimental Program}

Samples of uranium oxide material were removed from four different storage containers, 
combined, and mixed in a single container before the characterization and dissolution studies were initiated. An initial laboratory study was performed to identify a set of flowsheet conditions needed to maximize the potential for hydrogen generation.

The majority of the dissolution studies was conducted to obtain dissolving characteristics for these uranium oxide materials in low-molar nitric acid solutions. The preliminary hydrogen generation study was performed to supply C-Lab with a set of flowsheet conditions for measuring hydrogen generation rates (Reference 1). The generation of heat during dissolution was examined at ambient temperatures.

Nitric acid solutions were analyzed before and after the dissolution of uranium for free nitric acid concentrations. The final nitric acid solutions were analyzed by Inductively Coupled PlasmaEmission Spectroscopy (ICP-ES) and Inductively Coupled Plasma-Mass Spectroscopy (ICP-MS) to determine the uranium in solution and to identify impurities that may have dissolved during the dissolution cycles. Other analyses of final nitric acid solutions involved Rad Screen (RS) and gamma spectroscopy to determine plutonium concentrations.

The initial and final solids were analyzed by X-Ray Diffraction (XRD) to identify specific compounds. Solids that remained after the dissolution cycles were analyzed by XRD and Scanning Electron Microscopy (SEM). Results from the SEM studies were used to identify elements with an atomic number above fluorine that remained in the solids. Results from the XRD studies confirmed that only oxides were present.

The second set of dissolution experiments was conducted to provide information needed to complete material balance calculations. The flowsheet conditions used to dissolve uranium oxide materials during the initial studies include the set of flowsheet conditions that were used to dissolve solids during the material balance experiments. The final set of flowsheet conditions is recommended to HB-Line for use during dissolution of the uranium oxide materials in Phase I dissolvers.

\section{Discussion of Experimental Results}

\section{Hydrogen Generation}

Results from the laboratory experiment that was conducted to establish if hydrogen is generated during dissolution of these uranium oxide residues in low-molar nitric acid solutions without fluoride, were reported in Reference (2). Although the generation of hydrogen was not expected when only oxides are present, the presence of trace amounts of metal impurities could not be ruled-out. The conditions for the hydrogen generation study were based on dissolution in twomolar nitric acid and a final mass-to-volume ratio of 100 grams uranium in one liter of solution. This bounding set of flowheet conditions was identified in the Technical Task Request (Reference 3). The dissolution in low-molar nitric acid solutions would maximize the potential for hydrogen generation.

Hydrogen was not generated during the dissolution of these uranium oxide materials in two-molar nitric acid for two hours at $60-70^{\mathrm{O}} \mathrm{C}$. No gases were collected in the glass collection vial after the first hour. Since an unknown residue remained, the solids were heated for an additional hour before the experiment was terminated.

\section{Dissolving Studies}


A summary of results obtained during dissolution of uranium oxides is presented in Table I. The following three equations were used to explain results presented in Table I.

(1) $\mathrm{UO}_{2}+4 \mathrm{HNO}_{3} \rightarrow \mathrm{UO}_{2}\left(\mathrm{NO}_{3}\right)_{2}+2 \mathrm{NO}_{2}+2 \mathrm{H}_{2} \mathrm{O}$

(2) $\mathrm{UO}_{3}+2 \mathrm{HNO}_{3} \rightarrow \mathrm{UO}_{2}\left(\mathrm{NO}_{3}\right)_{2}+\mathrm{H}_{2} \mathrm{O}$

(3) $\mathrm{U}_{3} \mathrm{O}_{8}+8 \mathrm{HNO}_{3} \rightarrow 3 \mathrm{UO}_{2}\left(\mathrm{NO}_{3}\right)_{2}+2 \mathrm{NO}_{2}+4 \mathrm{H}_{2} \mathrm{O}$

Based on equations (2) and (3), the dissolution in one liter of 100 grams of uranium from these uranium oxide residues will consume a maximum of 1.14 moles of nitric acid.

Table I. The Dissolution of Uranium Oxides in Nitric Acid Solutions

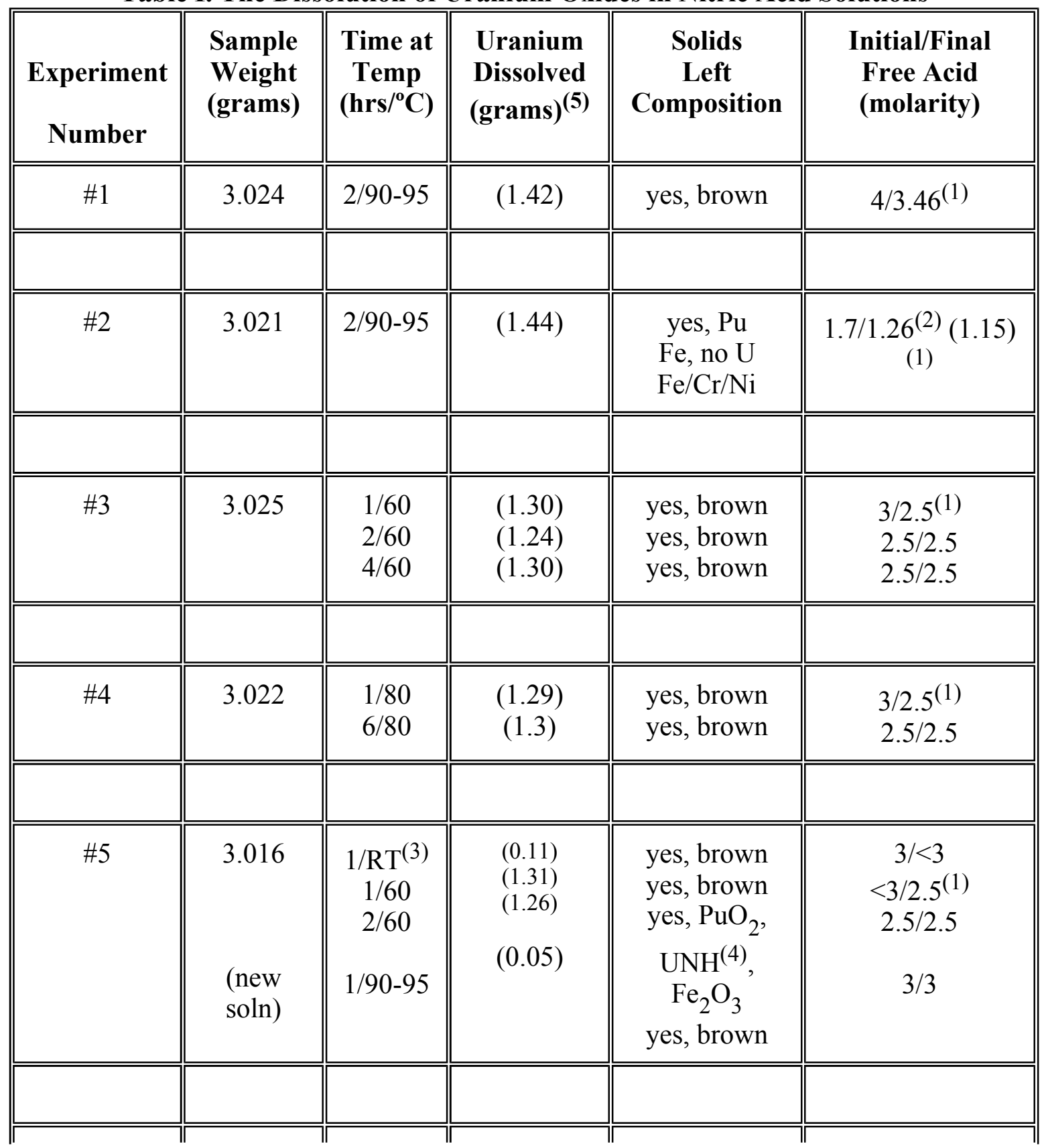




\begin{tabular}{|c|c|c|c|c|c|}
\hline \#6 & 3.022 & $\begin{array}{c}1 / \mathrm{RT} \\
1 / 40 \\
2 / 40 \\
1 / 90-95\end{array}$ & $\begin{array}{c}(0.13) \\
(1.40) \\
(1.39) \\
(0.002)\end{array}$ & $\begin{array}{c}\text { yes, brown } \\
\text { yes, brown } \\
\text { yes, brown } \\
\text { yes, brown } \\
\text { yes, } \mathrm{Pu}, \mathrm{Fe} \text {, } \\
\text { no U, } \\
\mathrm{Fe} / \mathrm{Cr} / \mathrm{Ni}\end{array}$ & $\begin{array}{c}2.85 /<2.85 \\
<2.85 / 2.32^{(1)} \\
2.32 / 2.38^{(2)} \\
3 / 3\end{array}$ \\
\hline
\end{tabular}

(1) Calculated free acid molarity.

(2)Both initial and final free acid concentrations measured in

Experiments \#2 and \#6.

(3)Room temperature or ambient temperature conditions.

(4)Uranyl nitrate hexahydrate (UNH).

(5)The amount of uranium measured in solution in Table I was not used

to establish the wt.\% uranium reported in the conclusion section.

The first dissolution experiment (\#1) was a screening study to observe what would happen when this material was added to nitric acid. After stirring at ambient temperature for about five minutes, nothing appeared to be happening. No temperature increase occurred and no brown gas was observed. The brown solids suspended in solution masked the faint yellow color of any uranium in solution as the uranium oxides were slowly dissolving. Then the nitric acid solution was slowly heated to $95^{\mathrm{O}} \mathrm{C}$ and held at that temperature for two hours. At elevated temperatures, brown $\mathrm{NO}_{2}$ fumes slowly collected in the vapor space above the nitric acid solution. The final free acid concentration of 3.46 molar was calculated based on the dissolution of 1.42 grams of uranium as $\mathrm{U}_{3} \mathrm{O}_{8}$ using equation (3). The faint brown fumes that were observed were due to the same oxidation-reduction reaction occurring in equations (1) and (3).

Experiment \#2 was performed to determine if all of the uranium would dissolve in low-molar nitric acid solutions. Solids remaining after dissolution were analyzed by SEM. Plutonium, iron, and $\mathrm{Fe} / \mathrm{Cr} / \mathrm{Ni}$ particles were observed. Uranium was not found by this analysis. The difference between the calculated final free acid concentration of 1.15 molar and the measured final free acid concentration of 1.26 molar was the first indication that a small amount of free $\mathrm{UO}_{3}$ was present in the residue. The dissolution of uranium as $\mathrm{UO}_{3}$ consumes less nitric acid since no oxidationreduction reactions are occurring in equation (2). The presence of $\mathrm{UO}_{3}$ was subsequently confirmed in the XRD pattern for the original solids presented in Figure 1 (XRD Figure 1 attached at end of report).

The next two experiments were performed to establish the dissolving characteristics of these materials at lower temperatures. Results shown in Table I for Experiments \#3 and \#4 indicated that little, if any, additional uranium dissolved after the first hour.

The final two experiments were performed to optimize a set of flowsheet conditions that could be used in HB-Line Phase I dissolvers for the dissolution of these uranium oxide materials. Results presented in Table I for Experiments \#5 and \#6 indicated that the dissolution rate of these oxide materials at room temperature is slow. No increase in solution temperature was measured during the dissolution of approximately $10 \%$ of the uranium after one hour at ambient temperature. In both Experiments \#5 and \#6 a fresh nitric acid solution was used to dissolve remaining solids for one hour at $90-95^{\mathrm{O}} \mathrm{C}$. The difference between the calculated and measured final free acid 
concentration in Experiment \#6 could be explained by the presence of $\mathrm{UO}_{3}$ not associated with $\mathrm{U}_{3} \mathrm{O}_{8}$.

The solids that were examined by XRD during Experiment \#5 were taken after heating for two hours at $60^{\mathrm{O}} \mathrm{C}$. Solids analysis results presented in Table I identified the presence of $\mathrm{PuO}_{2}$ and $\mathrm{Fe}_{2} \mathrm{O}_{3}$. The remaining uranium was due to cross contamination from $\mathrm{UNH}$ and not due to undissolved $\mathrm{UO}_{3}$ or $\mathrm{U}_{3} \mathrm{O}_{8}$ (XRD Figure 2 attached at end of report).

The solids that were analyzed by SEM during Experiment \#6 were taken after the final dissolution step of one hour at $90-95^{\mathrm{O}} \mathrm{C}$ in a fresh nitric acid solution. Again the SEM scan did not find uranium; only $\mathrm{Pu}, \mathrm{Fe}$, and $\mathrm{Fe} / \mathrm{Cr} / \mathrm{Ni}$ particles were found.

\section{Material Balance Experiments}

Results from the second set of dissolution experiments were used to calculate the material balances that are presented in Table II. The additional studies included dissolution in concentrated hydrochloric acid $(\mathrm{HCl})$ iron oxide residues left after the hydrogen generation study (Experiment \#7). In addition, the uranium in solution was measured by ICP-MS rather than ICP-ES to better quantify the uranium in these materials. Then both nitric acid and hydrochloric acid solutions from the hydrogen generation experiments were submitted for uranium analysis using ICP-MS.

The starting nitric acid concentrations used in experiments \#8 and \#9 were increased to three molar to generate a final nitric acid concentration of about two molar. The time and temperature conditions were similar to those used during the hydrogen generation studies. Experiment \#10 included an additional dissolution step at $90-95^{\mathrm{O}} \mathrm{C}$ to match the flowsheet conditions previously suggested for use in Phase I dissolvers.

In order to complete material balance calculations for these uranium oxide residues, the wt. $\%$ of absorbed moisture and waters of hydration was measured by Thermogravimetric Analysis (TGA). Results for this study are also presented in Table II.

Table II. Material Balance Measurement Results

\begin{tabular}{|c|c|c|c|c|c|}
\hline $\begin{array}{c}\text { Experiment } \\
\text { Number }\end{array}$ & $\begin{array}{l}\text { Sample } \\
\text { Weight } \\
\text { (grams) }\end{array}$ & $\begin{array}{l}\text { Time at } \\
\text { Temp. } \\
\left(\text { hrs. } /{ }^{\circ} \mathrm{C}\right)\end{array}$ & $\begin{array}{c}\text { U/U3O8 } \\
\text { Dissolved } \\
\text { (wt.\%) }\end{array}$ & $\begin{array}{l}\text { Solids Left } \\
\text { (wt.\%) }\end{array}$ & $\begin{array}{c}\text { Initial } \\
\text { Free Acid } \\
\text { (molarity) }\end{array}$ \\
\hline Hydrogen & 2.115 & $2 / 60-70$ & $81.7 / 96.6^{(1)}$ & $\mathrm{Yes}^{(2)}$ & 2 \\
\hline $\begin{array}{c}\# 7 \\
\text { HCI }\end{array}$ & Unknown $^{(2)}$ & $2 / 30$ & $<0.7 / 0.83$ & none visible & $\mathrm{HCI}$ \\
\hline & & & & & \\
\hline & & & & & \\
\hline
\end{tabular}




\begin{tabular}{|c|c|c|c|c|c|}
\hline \#8 & 3.024 & $2 / 60$ & $79.5 / 94$ & yes, 3.4 & 3 \\
\hline \#9 & 3.01 & $2 / 60$ & $76.5 / 90.4$ & $\begin{array}{c}\text { yes, } 8.7 \\
\mathrm{U}, \mathrm{Pu}, \mathrm{Fe} \\
\mathrm{Fe}, \mathrm{Cr}, \mathrm{Ni}\end{array}$ & 3 \\
\hline \#10 & 3.23 & $\begin{array}{c}2 / 60-70 \\
+1 / 90-95\end{array}$ & $82.7 / 97.7$ & yes, 0.3 & 3 \\
\hline \#11 & 0.51 & $0.75 / 20-600$ & NA & 1.2( $\left(\mathrm{H}_{2} \mathrm{O}\right)$ lost & NA \\
\hline
\end{tabular}

(1)Uranium weights based on ICP-MS results.

(2)Unknown amount of brown solids left after hydrogen generation study dissolved in concentrated $\mathrm{HCl}$.

\section{Discussion of Table II Results}

Results obtained from experiment \#7 indicated that dissolution in two molar nitric acid for two hours at $60^{\mathrm{O}} \mathrm{C}$ will dissolve at least $99 \%$ of the total uranium. An additional dissolution step at 90$95^{\mathrm{O}} \mathrm{C}$ would have dissolved remaining uranium from these solids.

Results obtained from experiments \#8 and \#9 indicated that the wt.\% of insoluble iron compounds varies from sample to sample. The observation that undissolved uranium was identified by SEM in remaining solids after dissolution for two hours at $60^{\circ} \mathrm{C}$ suggests that additional dissolving at 90$95^{\mathrm{O}} \mathrm{C}$ may be required to complete the dissolution of uranium.

Results obtained from experiment \#10 appear to confirm the need to dissolve at higher temperatures to ensure complete uranium dissolution. Only $0.3 \mathrm{wt} \% \%$ solids remained after the additional dissolution cycle. The wt.\% uranium in this sample was the highest measured for this batch of material.

Results from experiment \#11 indicate that the water content in these uranium oxide materials is insufficient to account for the lower than expected wt.\% uranium. Only $1.2 \mathrm{wt} \%$ of this material is attributed to moisture content.

\section{Conclusions}

1. The flowsheet conditions that should complete the dissolution of uranium from these uranium oxide materials involve dissolution at $60-80^{\mathrm{O}} \mathrm{C}$ for at least two hours followed by dissolution at $90^{\mathrm{O}} \mathrm{C}$ to boiling for at least one hour in three molar nitric acid. The use of fluoride ions in the nitric acid solution is not necessary.

2. Based on results presented in Table II, these uranium oxide materials appear to contain 
approximately 80 wt. $\%$ uranium as a mixture of $\mathrm{U}_{3} \mathrm{O}_{8}$ and $\mathrm{UO}_{3}$.

3. The remaining wt. $\%$ in these uranium oxide materials consists of a mixture of $\mathrm{Fe}_{2} \mathrm{O}_{3}$ and $\mathrm{Fe} / \mathrm{Cr} / \mathrm{Ni}$ particles, waters of hydration, and absorbed moisture. Plutonium is a trace impurity.

4. Hydrogen is not generated during the dissolution of these uranium oxide materials.

5. No detectable heat was generated during the dissolution of these uranium oxide materials.

6. The dissolution of uranium from these uranium oxide materials at ambient temperatures is slow.

7. Brown, nitrogen dioxide $\left(\mathrm{NO}_{2}\right)$ gas will be generated during the dissolution of these uranium oxide materials.

8. The dissolution of 100 grams of uranium in one liter of nitric acid solutions will consume a maximum of 1.14 moles of nitric acid.

\section{References}

1. J. H. Gray, "C-Lab Hydrogen Generation Tests (U)", SRT-ATS-2003-00018, May 25, 2003.

2. S. Crump, "Gas Analysis Results", SRT-ADS-03-0297, May 20, 2003.

3. Technical Task Request No. NMMD-HTS-2003-221, "Flowsheet Development for Processing of Rocky Flats Oxide", April 29, 2003. 


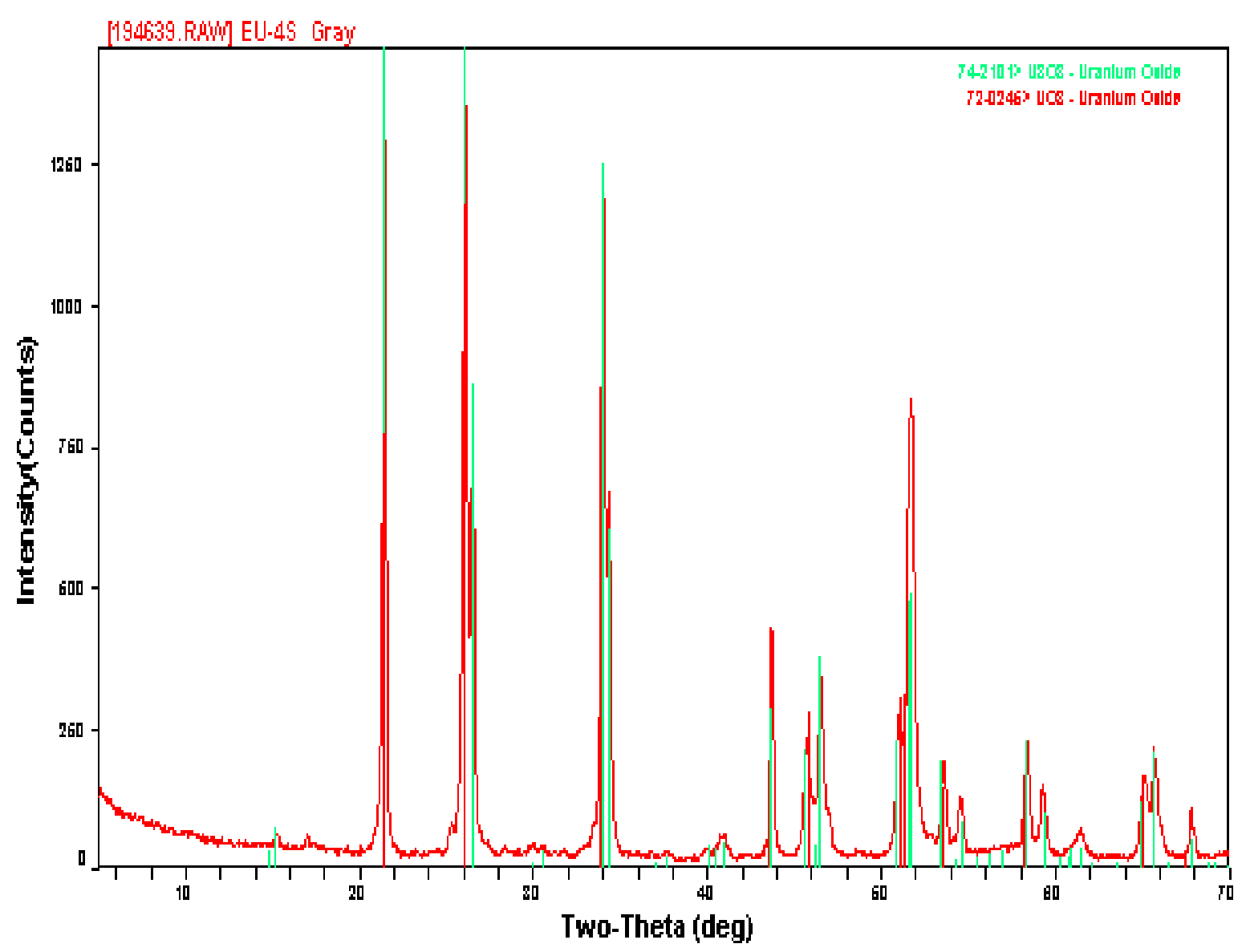

Figure 1 


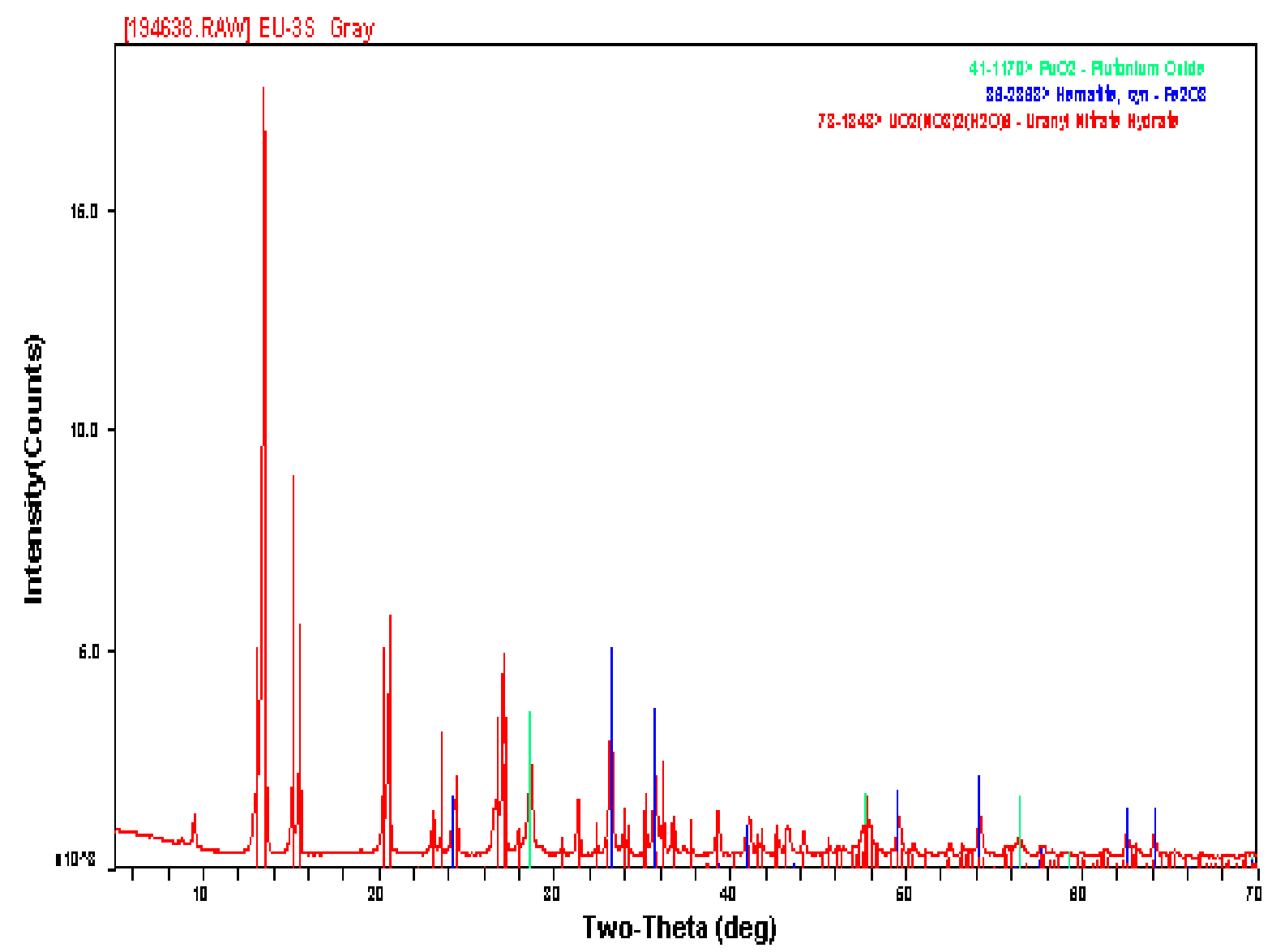

Figure 2 